\title{
METHOD FOR ACCELERATED LEACHING OF SOLIDIFIED WASTE
}

\author{
M. Fuhrmann, J.H. Heiser, R.F. Pietrzak, \\ E.M. Franz, and P. Colombo
}

November 1990

RADIOLOGICAL SCIENCES DIVISION

DEPARTMENT OF NUCLEAR ENERGY

BROOKHAVEN NATIONAL LABORATORY, ASSOCIATED UNIVERSITIES, INC.

UPTON, NEW YORK 11973

Prepared for the

NATIONAL LOW-LEVEL WASTE MANAGEMENT PROGRAM

UNITED STATES DEPARTMENT OF ENERGY 
This report was prepared as an account of work sponsored by an agency of the United States Government. Neither the United States Government nor any agency thereof. nor any of their employees, nor any of their contractors, subcontractors, or their employees, makes any warranty, express or implied, or assumes any legal liability or responsibility for the accuracy, completeness, or usefulness of any information. apparatus, product, or process disclosed, or represents that its use would not infringe privately owned rights. Reference herein to any specific commercial product, process, or service by trade name, trademark, manufacturer, or otherwise, does not necessarily constitute or imply its endorsement, recommendation, or favoring by the United States Government or any agency, contractor or subcontractor thereof. The views and opinions of authors expressed herein do not necessarily state or reflect those of the Inited States Government or any agency, contractor or subcontractor thereof.

Printed in the United States of America

Available from

National Technical Information Service

U.S. Department of Commerce

5285 Port Royal Road

Springfield, VA 22161

NTIS price codes:

Printed Conv: A02: Microfiche Copy: A01 


\begin{abstract}
An accelerated leach test method has been developed to determine the maximum leachability of solidified waste. The approach we have taken is to use a semi-dynamic leach test; that is, the leachant is sampled and replaced periodically. Parameters such as temperature, leachant volume, and specimen size are used to obtain releases that are accelerated relative to other standard leach tests and to the leaching of full-scale waste forms. The data obtained with this test can be used to model releases from waste forms, or to extrapolate from laboratory-scale to full-scale waste forms if diffusion is the dominant leaching mechanism. Diffusion can be confirmed as the leaching mechanism by using a computerized mathematical model for diffusion from a finite cylinder. We have written a computer program containing several models including diffusion to accompany this test. The program and a Users' Guide that gives screen-by-screen instructions on the use of the program are available from the authors.
\end{abstract}




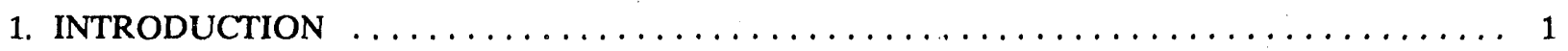

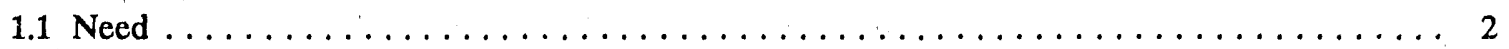

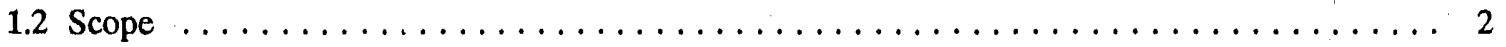

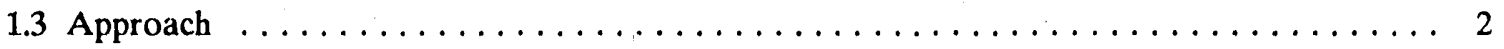

2. EQUIPMENT AND MATERIALS $\ldots \ldots \ldots \ldots \ldots \ldots \ldots \ldots \ldots \ldots \ldots \ldots \ldots \ldots$

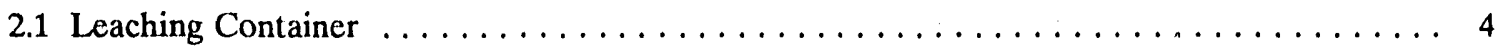

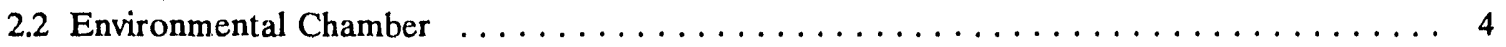

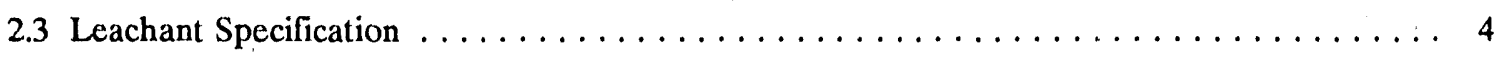

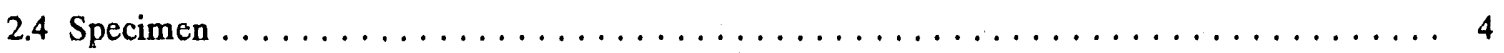

3. ACCELERATED LEACH TEST METHOD $\ldots \ldots \ldots \ldots \ldots \ldots \ldots \ldots \ldots \ldots \ldots \ldots$

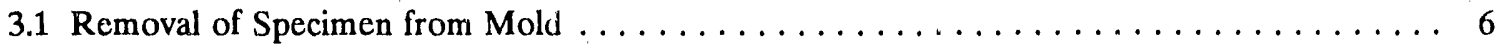

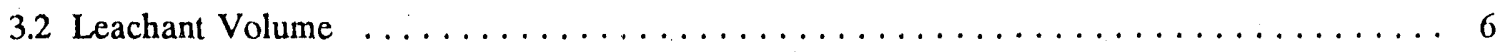

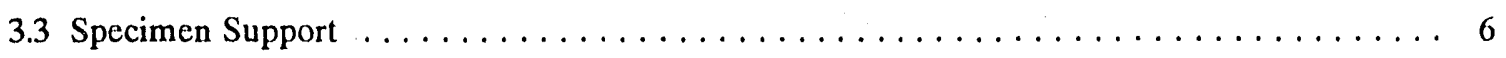

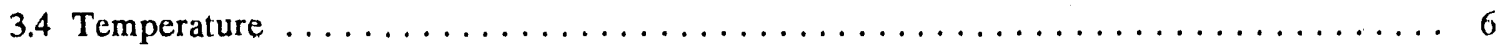

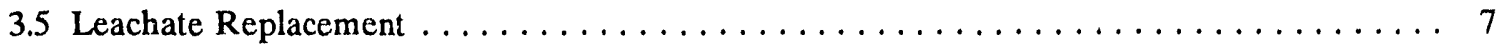

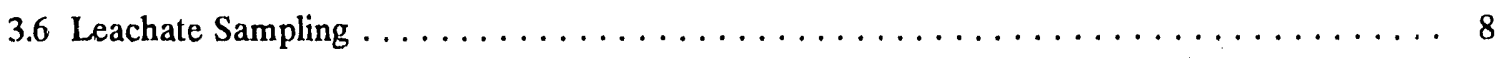

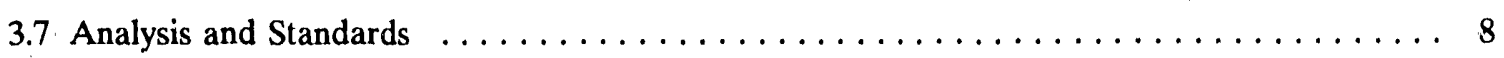

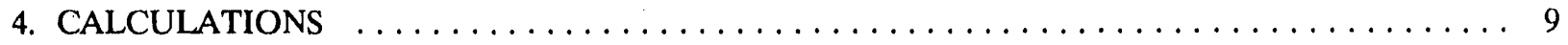

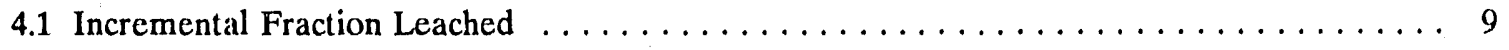

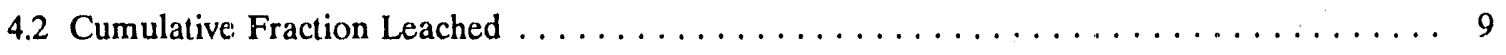

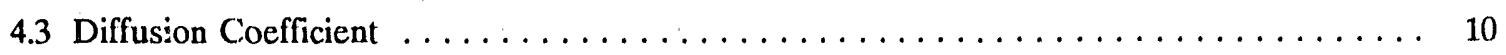

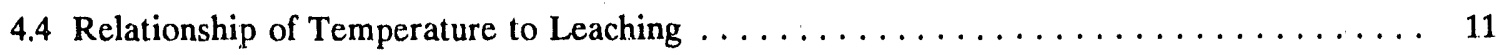

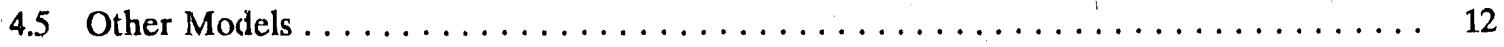

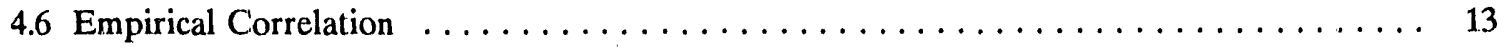

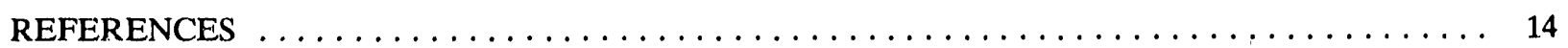

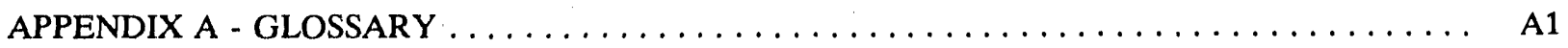




\section{List of Figures}

Figure 1. A schematic of the concepts used to combine experimental and modeling approaches. ..... 3

Figure 2. The Cumulative Fraction Leached plotted versus Time. The top of the plot $(C F L=1)$

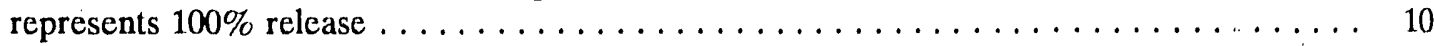

Figure 3. An example of an Arrhenius plot showing the y-axis as the logarithm of the effective diffusion coefficient, De, and the $\mathrm{x}$-axis as the reciprocal of absolute temperature. This figure is for Sr-85 leaching from a cement waste form and indicates that there is a linear relationship between the data and temperature to $65^{\circ} \mathrm{C}(\mathrm{X}=2.95)$.

Figure 4. Plotting cumulative fraction leached (CFL) from the accelerated test as a function of the CFL from the reference test $\left(20^{\circ} \mathrm{C}\right)$ will produce a straight line if the leaching mechanism has not changed.

List of Tables

TABLE 1 Replacement Intervals for the Leachant 


\section{INTRODUCTION}

Leachability is an important factor in evaluating the safety, acceptability, and environmental impacts of radionuclides from solidified waste. Leachability is assessed by carrying out a leach test to directly meisure the release of radionuclides (or an inactive analog), into an aqueous medium as a function of time.

The choice of test methods is generally governed by the use to which the results are to be put. The major applications for test results are:

- comparison of various solidification agents,

- optimization of formulations for waste to binder ratios,

- compliance with regulatory requirements,

- quality assurance in solidification plant operations,

- radiological assessment of waste disposal, and

- understanding of the leaching mechanism(s).

Thus, a wide variety of test methods have been developed and adopted in response to local requirements. Static tests, such as the MCC-1 [1], do not require replacement of the leachant and are used to determine solubility limits. Flow-through tests, such as the MCC-4 [2] provide continuous change of leachant to maximize releases by maintaining minimal radionuclide concentrations in the leachant. The ANS 16.1 [3] and the IAEA [4] tests are semidynamic tests, and achieve similar objectives by prescribing changes in the leachant at regular intervals. Both the flow-through and the semidynamic tests attempt to provide a measure of the intrinsic property of the material, namely the net forward leach rate. Generally, this rate is expressed as a diffusion coefficient. However, no leach test has any means of determining if leaching actually takes place through diffusion or other mechanisms. Without such knowledge for specific waste form materials, no extrapolations can be made using models of leaching mechanisms. The accelerated leach test described here combines experimental and modeling approaches to analyzing leaching processes. It provides the experimental conditions needed to determine if diffusion is the leaching mechanism, as well as a computer program with models to analyze the data.

Many of the concepts used in the development of this test method are similar to those outlined independently in ASTM Standard Practice E632-82 entitled "Developing Accelerated Tests to Aid Prediction of the Service Life of Building Components and Materials" [5]. Publications describing the studies to determine the effectiveness of factors that accelerate leaching and their influence on leaching mechanisms can be found in references 6-12. 
1.1 Need

These are insufficient data to provide a basis for adequately assessing the long-term leaching behavior of solidified waste forms in aqueous environments. With recent emphasis on source term analysis and assessment of disposal site performance, there is an urgent need for a reliable, short-term test to predict long. term leachability.

\subsection{Scope}

This test gives an accelerated determination of the maximum leachability of solidified waste. The method is applicable to any material that does not degrade, deform, or in which there is no change in the mechanism of leaching during the test.

The data obtained with this test can be used to model long-term releases from waste forms, or to extrapolate from laboratory-scale to full-scale waste forms if diffusion is the dominant leaching mechanism. Diffusion can be confirmed as the leaching mechanism by using a computerized mathematical model for diffusion from a finite cylinder. We have written a computer program containing several models including diffusion to accompany this test. The program, and a User's Guide [13] that gives screen-by-screen instructions on the use of the program, are available. The models used in the program are described in Appendix A of the User's Guide.

The results do not apply to releases in specific disposal environments unless tests are conducted to determine the leaching mechanism under those conditions. Projections of releases require the long-term stability of the waste form, which may not be revealed adequately by short-term tests.

\subsection{Approach}

The approach we have taken is to use a semi-dynamic leach test; that is, the leachant is sampled and replaced periodically. Parameters such as temperature, leachant volume, and specimen size are used to obtain releases that are accelerated relative to other standard leach tests and to the leaching of full-scale waste forms.

The results of this accelerated test can be extrapolated to long times if the data from tests run at high temperatures $\left(50^{\circ} \mathrm{C}\right)$ and those run at the reference temperature $\left(20^{\circ} \mathrm{C}\right)$ can be modeled by diffusion. A computer program plots the experimental data and a curve calculated from an effective diffusion coefficient for diffusion from a finite cylinder (Figure i). If the data from the accelerated tests, the reference test, and the 
modeled curve fit within defined criteria, diffusion is taken to be the leaching mechanism. In this case, the model can be used to project releases from full-scale waste forms for long times. The accelerated test provides a measure of the maximum fractional release to which the modeled data can be extrapolated. By generating data over a specified temperature range, an Arrhenius plot can be produced, allowing projections at temperatures other than those tested. If the diffusion model cannot fit the data, other models (diffusion plus partitioning and solubility limited) can be used to suggest the leaching mechanism that controls releases; no extrapolations are allowed with these models. If no model fits the data, then an alternative graphical comparison of the data is recommended. A linear plot of modeled CFL plotted against experimental CFL verifies that the accelerated data is comparable to the reference data, showing that the accelerated test is appropriate; with this technique, no extrapolation of data can be made.

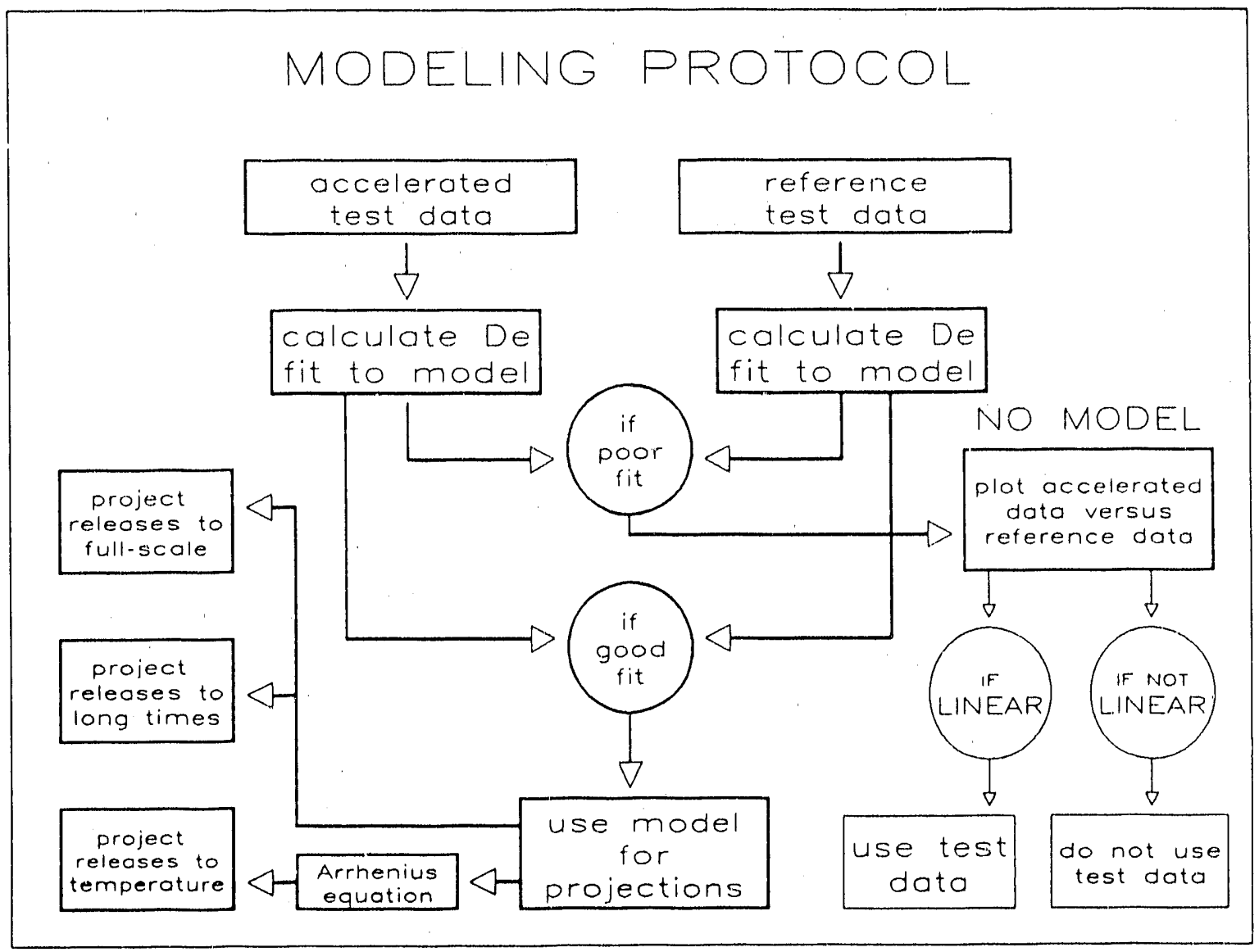

Figure 1. A schematic of the concepts used to combine experimental and modeling approaches. 


\section{QUIPMENT AND MATERIALS}

\section{$2.1 \quad$ Leaching Container}

Any container is suitable in which to conduct the leach test provided it does not react with the leachant/leachate and does not adsorb significant quantities of the species of interest. We found high density polyethylene to be a suitable material. The top of the container should fit tightly to ensure that evaporative losses are less than $1 \%$ over 24 hours.

\subsection{Environmental Chamber}

The temperature of the leachant should be controlled to $\pm 1^{\circ} \mathrm{C}$ of the cesignated test temperature. A forced air environmental chamber or a circulating water bath is recommended.

\subsection{Leachant Specification}

The leachant should be distilled or deionized water that meets or exceeds standards for types II or III reagent water, as specified in ASTM D1193 [14].

\section{$2.4 \quad$ Specimen}

Specimens should be right circular cylinders with a diameter-to-height ratio between 1:1 and 1:2. (A convenient size is $2.5 \mathrm{~cm}$ diameter by $2.5 \mathrm{~cm}$ height.) Smaller sizes result in problems of mixing and produce inhomogeneous samples.

Specimens should be representative of the full-scale solidified waste form and prepared using the techniques. Particular attention should be paid to ensuring that the laboratory specimen is homogeneous. Curing conditions, especially the temperatures experienced by the large waste forms, should be duplicated. Care should be taken to assure that surfaces of the laboratory specimens reflect the structure of surfaces of large waste forms, that is, surfaces that are cast against container walls as opposed to free or cut surfaces.

At least three specimens should be tested at each temperature.

$$
4-
$$


The dimensions, weight, composition, and curing history should be recorded for each specimen, and an accurate determination made of the source term $\left(\mathrm{A}_{0}\right)$, that is, the amount of activity in the specimen at the start of the leach test. 


\section{ACCELERATED LEACH TEST METHOD}

\subsection{Removal of Specimen from Mold}

After removing the specimen from the container or mold in which ir was made, any excess material should be removed before weighing the specimen. The mold should be rinsed in a volume of water equal to the volume of the specimen. If the activity in the rinse water represents more than $0.5 \%$ of the total activity contained in the specimens, the activity of the rinse water should be subtracted from the source term $\left(A_{0}\right)$.

\subsection{Leachant Volume}

The leachant volume used for each interval should be 100 times the surface area of the specimen as calculated bciow:

$$
\frac{\text { Leachant volume }\left(\mathrm{cm}^{3}\right)}{\text { Specimen surface area }\left(\mathrm{cm}^{2}\right)}=100 \pm 2 \mathrm{~cm}
$$

This ratio requires a large volume of water, for example, a specimen that is $2.5 \mathrm{~cm}$ in diameter $\times 2.5 \mathrm{~cm}$ in height has a surface area of approximately $30 \mathrm{~cm}^{2}$, giving a leachant volume of $3000 \mathrm{ml}$.

\subsection{Specimen Support}

The specimen shall be positioned in the leachant container so that it is in the upper portion of the leachant. The support should be made of non-reactive material, and should not impede leaching by obstructing the surface area of the specimen by more than $1 \%$. Moreover, it should not interfere with replacement of the leachate.

One method is to suspend the specimen from the top of the container. A string is tied around the specimen and the free end passed through a small hole in the container cover and secured; the hole is sealed to prevent evaporation.

\subsection{Temperature}

Elevated temperatures can be used with the accelerated leach test to increase leaching. For materials and formulations that have not been previously tested, tests should be conducted at a minimum of three 
temperatures (one of which should be $20^{\circ} \mathrm{C}$ ) to establish that leaching increases systematically with higher temperatures. The recommended maximum temperature is $50^{\circ} \mathrm{C}$, which is below the threshold of anomalous releases observed so far [6]. Temperatures above the maximum recommended can be used if it is demonstrated that releases follow the trend observed at lower temperatures.

\subsection{Leachate Replacement}

The time when the specimen is first placed in the leachant should be noted, and the leachant replaced at the intervals shown in Table 1. The leachant should be brought to the test temperature before the specimen is placed in it.

TABLE 1

Replacement Intervals for the Leachant

\begin{tabular}{ccc} 
Interval & Incremental Time (t) & Cumulative time $(\Sigma \mathrm{t})$ \\
\cline { 2 - 3 } 1 & 2 hours $\pm 5 \%$ & 2 hours \\
2 & 5 hours $\pm 5 \%$ & 7 hours \\
3 & 17 hours $\pm 2 \%$ & 1 day \\
4 & 1 day $\pm 2 \%$ & 2 days \\
5 & 1 day $\pm 2 \%$ & 3 days \\
6 & 1 day $\pm 2 \%$ & 4 days \\
7 & 1 day $\pm 2 \%$ & 5 days \\
8 & 1 day $\pm 2 \%$ & 6 days \\
9 & 1 day $\pm 2 \%$ & 7 days \\
10 & 1 day $\pm 2 \%$ & 8 days \\
11 & 1 day $\pm 2 \%$ & 9 days \\
12 & 1 day $\pm 2 \%$ & 10 days \\
13 & 1 day $\pm 2 \%$ & 11 days
\end{tabular}

If the specimen is suspended from the container top as described, the most convenient method of changing the leachant is to lift off the cover (with the specimen attached) and place it on a new container full of fresh leachant. The new container (with the specimen) then can be replaced in the temperature-controlled environment, and the leachate in the old container sampled. During changes, the specimen should be exposed to air for as short a time as possible to minimize reactions with air (e.g., carbonation of cement specimens). 


\subsection{Leachate Sampling}

Imnediately after the specimen has been moved to fresil water, the old leachate should be stirred thoroughly and sampled to minimize any artifacts caused by cooling (e.g. precipitation). These samples will be used to determine the quantities of the species of interest that have leached from the specimens during each interval and should be appropriately preserved for the analyses. This may require that seyeral aliquots be taken at each sampling. If significant amounts of particulates are present in the leachate, it is necessary to account for the activity associated with the particulates.

\subsection{Analysis and Standards}

Arialysis of species in the leachate will be conducted by standard methods. Appropriate standards should be used for analysis. If necessary, standards should be prepared to match the matrix elements in the samples. For radioactive specimens, the preferred method of analysis includes the use of a standard prepared from dilutions of an aliquot of the original solution (or waste) used to make the specimens. With this method, leachate samples can be counted relative to standards and without the need for absolute standards and knowledge of ietector efficiencies. 


\section{CALCUlations}

\subsection{Incremental Fraction Leached}

Several parameters can be calculated from the data obtained. The incremental fraction leached (IFL) is calculated by the following equation:

$$
\mathrm{IFL}=\frac{\mathrm{a}_{\mathrm{n}}}{\hat{A}_{0}}
$$

where,

$a_{n} \quad$ is the quantity of a species observed in the leachate at any given interval. This value is corrected for radioactive decay to the time of the beginning of the test.

$A_{0}$ is the source term, the total original quantity contained in the leaching specimen at the beginning of the test.

The rate of release for any interval can be calculated by dividing IFL by the elapsed time. The rate can then be divided by the surface area of the specimen to obtain the fraction released per square centimeter per second.

\subsection{Cumulative Fraction Leached}

Another parameter is cumulative fraction leached, which is calculated as:

$$
\mathrm{CFL}=\frac{\Sigma \mathrm{a}_{\mathrm{n}}}{\mathrm{A}_{0}}
$$

which is the sum of the fractions of all activity leached during the test. This value for each interval, plotted as a function of cumulative time, provides a useful means of graphically compaing data to other test results and to modeling results. An example of this type of plot is shown in Figure 2. 


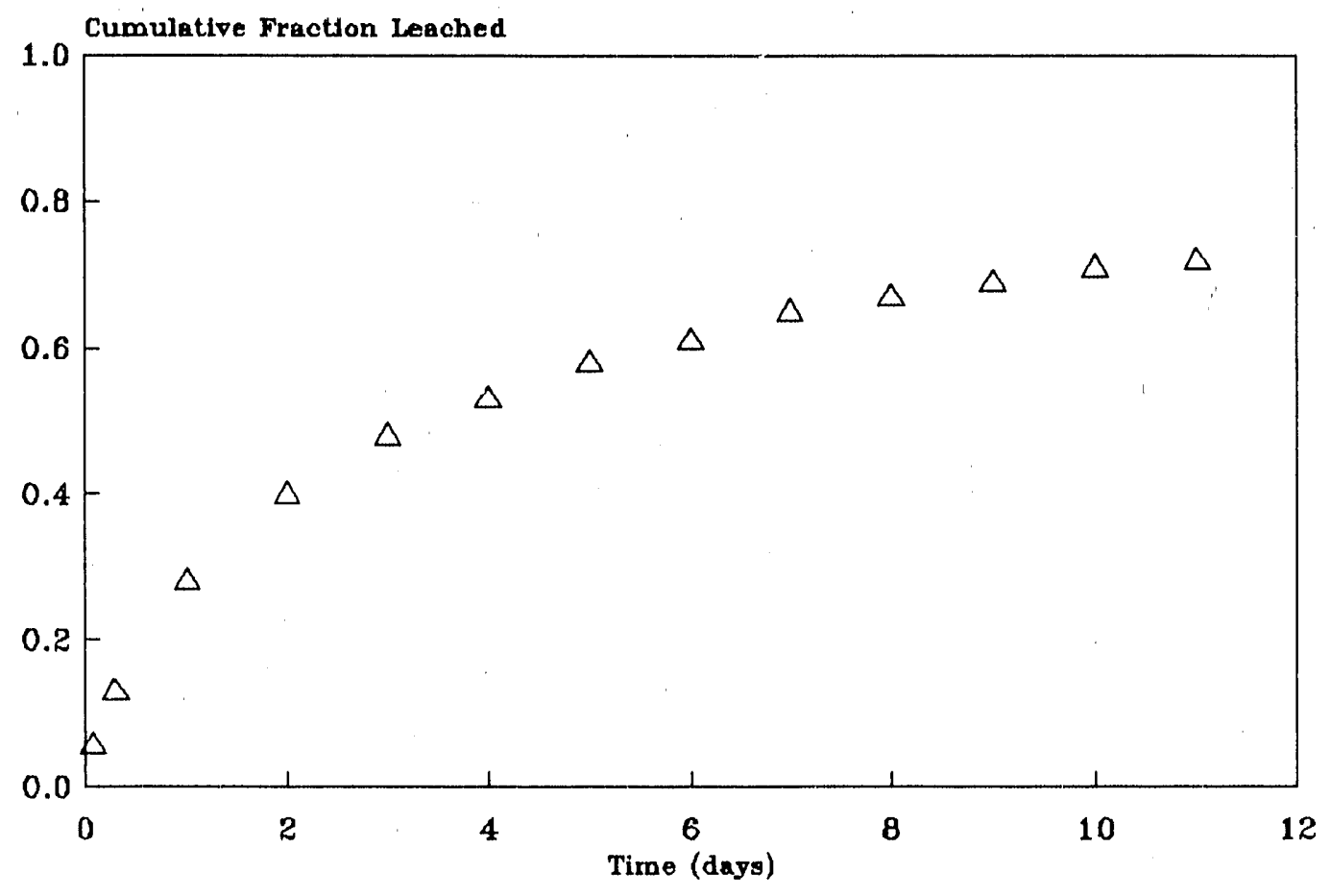

Figure 2. The Cumulative Fraction Leached plotted versus Time. The top of the plot $(\mathrm{CFL}=1)$ represents $100 \%$ release.

\subsection{Diffusion Coefficient}

This test has an associated computer program that calculates an optimized effective diffusion coefficient based on the solution to diffusion from the finite cylinder (see Appendix $A$ in reference 13). The computer program optimizes the calculation of $D_{e}$ from the test data so that the curve $\Sigma a_{n} / A_{0}$ calculated from $D_{e}$ can be plotted against time and readily compared to the data itself. This should be done for data from the accelerated test and from the reference test. If the curves of the data and the model all fall within a designated value describing "goodness of fit," then it can be concluded that diffusion is the dominant leaching mechanism. In this case, the model can be used to project releases to long times. This projection assumes that the waste form remains intact and the leaching mechanism does not change with time.

The "goodness of fit" of the model to the data is determined by calculating the sum of the residuals between the optimized model curve and the experimental data. The sum of the residuals is expressed as $E_{R}$, which is a percentage of the final CFL value of the experimental data. With a perfect fit of the model to the 
data, $E_{R}$ will be zero. $A$ value of $E_{R}$ equal to or less than $0.5 \%$ is taken to mean that the diffusion model accurately represents the data.

\subsection{Relationship of Temperature to Leaching}

Elevated temperatures can be used with the accelerated leach test to accelerate releases from specimens; consequently, the leach rate must show a positive and predictable relationship to increasing temperature. Leach tests run at elevated temperatures provide a maximum value of CFL to which the projections made with the models are limited. This approach is acceptable only when the data taken at $20^{\circ} \mathrm{C}$ and at the higher temperatures can be described by the diffusion model.

Theoretically, the temperature dependence of a chemical process, in this case leaching, as expressed by the diffusion coefficient $D_{e}$, depends on the Arrhenius equation:

$$
D_{e}=A \exp -E_{a} / R T
$$

where,

$D_{e}=$ effective diffusion coefficient at $T$

$$
\begin{aligned}
& A=\text { constant } \\
& E_{a}=\text { activation energy in } \mathrm{kcal} / \text { mole } \\
& R=\text { gas constant } \\
& T=\text { temperature in degrees kelvin }
\end{aligned}
$$

From this equation, diffusion coefficients determined from experiments conducted at varying temperatures are plotted on a log scale against $1 / \mathrm{T}$ (Kelvin), as shown in Figure 3. A linear plot shows that the increase in leaching is proportional to the increase in temperature. This linear relationship means that:

1) the leaching mechanism, as well as the structural controls on leaching (e.g. tortuosity and porosity) are unchanged by increasing temperature, and

2) diffusion coefficients can be calculated for temperatures other than those tested.

If elevated temperatures are to be used, it must be demonstrated that a linear relationship exists on the Arrhenius plot for each material tested. In some cases, the plot may not be linear at elevated temperatures. This effect can limit the maximum test temperature. For all materials, the relationship of leaching to elevated temperature must be determined for at least three points to ascertain that the maximum temperature used is 
mechanistically acceptable. A convenient maximum temperature is $50^{\circ} \mathrm{C}$, although in some cases a lower temperature is required to conserve the leaching mechanism [6].

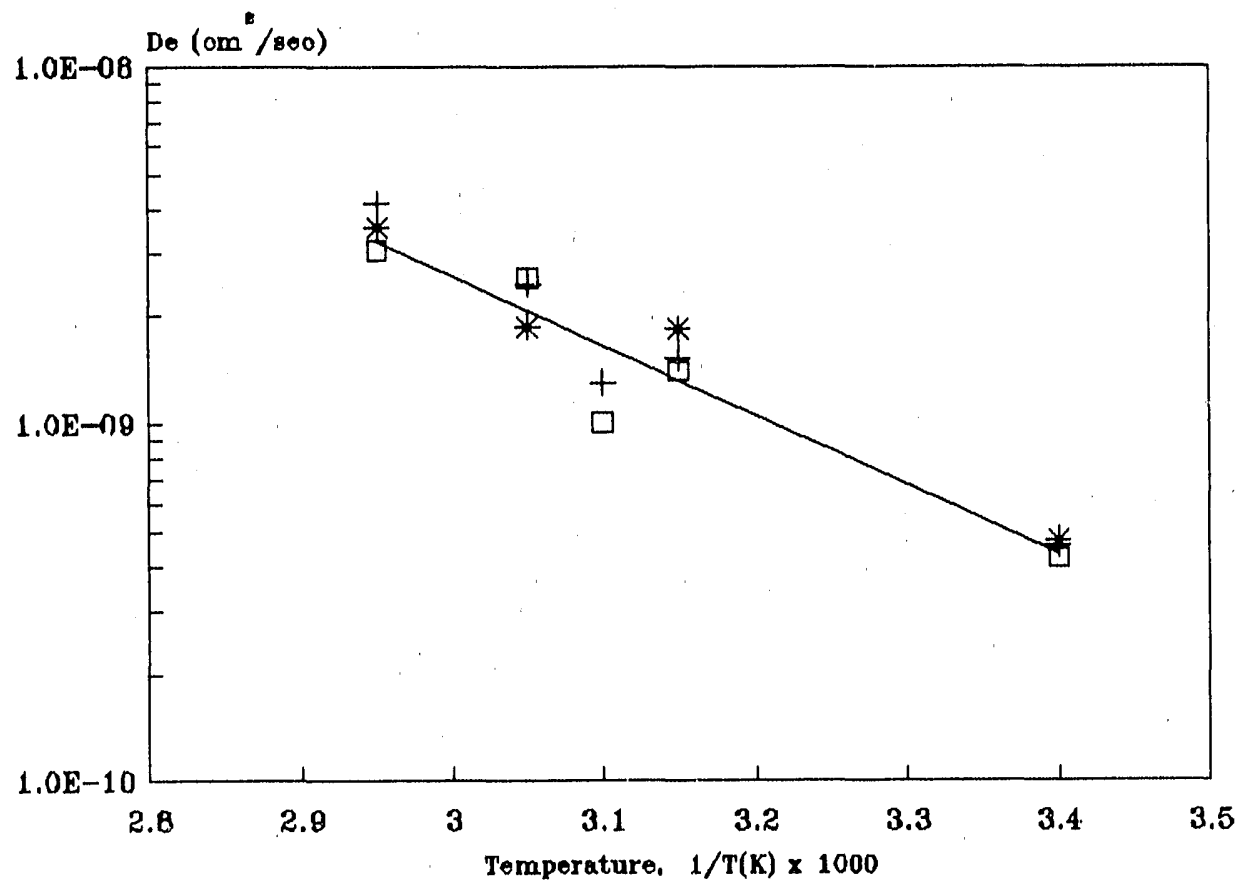

Figure 3. An example of an Arrhenius plot showing the y-axis as the logarithm of the effective diffusion coefficient, De, and the $\mathrm{x}$-axis as the reciprocal of absolute temperature. This figure is for $\mathrm{Sr}-85$ leaching from a cement waste form and indicates that there is a linear relationship between the data and temperature to $65^{\circ} \mathrm{C}(X=2.95)$.

\subsection{Other Models}

The computer program that accompanies this test method contains two models in addition to the two diffusion models. One model partitions the source term into a leachable component and an unleachable component, and then uses the diffusion models to determine releases from the leachable portion. The other model determines if solubility constraints are limiting leaching. This model produces a graph of incremental fraction leached plotted as a function of time. Both models are described in Appendix A of the User's Guide 
[13]. Although the partition model allows extrapolation of releases based on the leachable fraction of the source term, neither the partitioning model nor the solubility model should be used to make projections. Rather, these models are intended to suggest if mechanisms other than simple diffusion are controlling releases.

\subsection{Empirical Correlation}

If the data and the model do not provide a good fit, indicating that diffusion is not the leaching mechanism, an empirical approach can be taken to compare releases from tests at elevated temperature with releases from reference tests at $20^{\circ} \mathrm{C}$. This comparison is done by plotting CFL from the accelerated test on the $y$-axis of a graph and CFL from the reference test on the $x$-axis. The points are matched according to interval. If this scatter plot results in a linear graph, the data from the two tests can be compared and the results of the accelerated test can be said to accurately reflect the data from the reference test. An example is shown in Figure 4. However, this method of correlation cannot be used to extrapolate the data to long times.

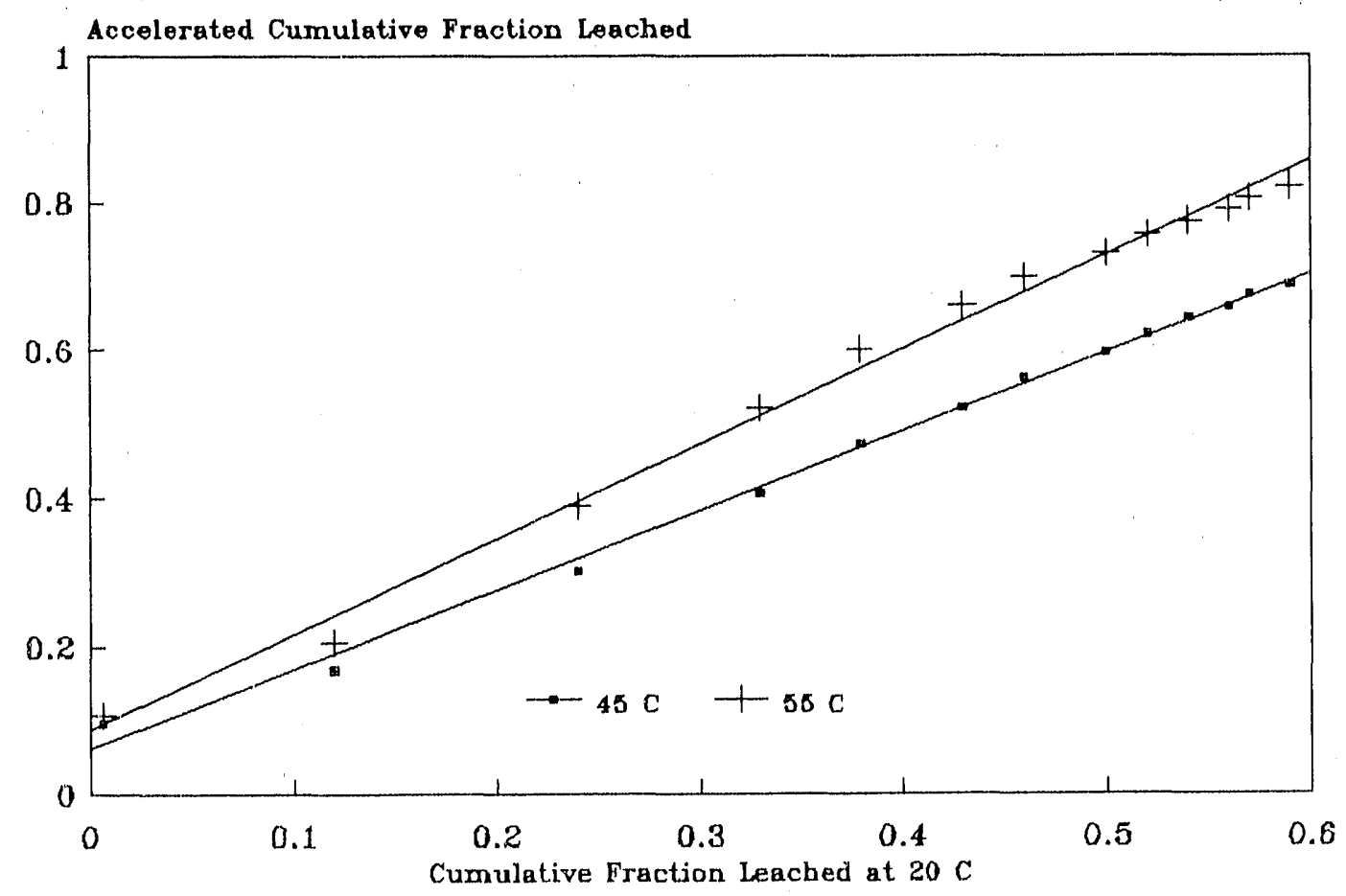

Figure 4. Plotting cumulative fraction leached (CFL) from the accelerated test as a function of the CFL from the reference test $\left(20^{\circ} \mathrm{C}\right)$ will produce a straight line if the leaching mechanism has not changed. 


\section{REFERENCES}

1. Materials Characterization Center, MCC-1s Static Leach Test, Pacific Northwest Laboratory, Richland, WA, August 1980.

2. Materials Characterization Center, MCC-4s Low-Flow-Rate Leach Test Method, Pacific Northwest Laboratory, Richland, WA, September 1981.

3. American Nuclear Society, "Measurement of the Leachability of Solidified Low-Level Radioactive Wastes by a Short-Term Test Procedure," ANSI/ANS 16.1-1986, American Nuclear Society, 555 North Kensington Avenue, La Grange Park, Illinois 60525, April 1986.

4. Hespe, E.D., "Leach Testing of Immobilized Radioactive Waste Solids, A Proposal for a Standard Method," Atomic Energy Review, Vol. 9, No. 1, pp. 195-207, April 1971.

5. American Society for Testing and Materials, "Standard Practice for Developing Accelerated Tests to Aid Prediction of the Service Life of Building Components and Materials," E632-82, Annual Book of ASTM Standards, Vol. 04.07, pp. 630-637, ASTM, 1916 Race Street, Philadelphia, PA 19103, 1983.

6. Fuhrmann, M., Pietrzak, R.F., Franz, E.M., Heiser, J.H. and Colombo, P., "Optimization of the Factors that Accelerated Leaching," Topical Report, BNL-52204, Brookhaven National Laboratory, Upton, New York 11973, March 1989.

7. Pietrzak, R.F., Fuhrmann, M., Franz, E.M., Heiser, J.H. and Colombo, P., "Accelerated Leach Testing of Radionuclides from Solidified Low-Level Waste," BNL-42121, Presented at the American Chemical Society Meeting, Dallas, Texas, April 9-14, 1989.

8. Fuhrmann, M., Pietrzak, R.F., Heiser, J.H., Franz, E.M. and Colombo, P., "Development of an Accelerated Leach Test," BNL-41893, In: Waste Management '89, Volume 2, R. Post and M. Wacks (editors) pages 305-309, University of Arizona, Tucson, Arizona, 1989.

9. Dougherty, D., Pietrzak, R.F., Fuhrmann, M., and Colombo, P., "An Experimental Survey of the Factors that Affect Leaching from Low-Level Radioactive Waste Forms," Topical Report, BNL 52125, Brookhaven National Laboratory, Upton, New York 11973, September 1988.

10. Dougherty, D., Pietrzak, R.F., Fuhrmann, M. and Colombo, P., "Accelerated Leach Test(s) Program," Annual Report, BNL-52042, Brookhaven National Laboratory, Upton, New York 11973, Sept umber 1986. 


\section{REFERENCES (cont'd)}

11. Dougherty, D.R. and Colombo, P., "Leaching Mechanisms of Solidified Low-Level Waste, The Literature Survey," BNL-51899, Brookhaven National Laboratory, Upton, New York 19973, June 1985.

12. "Dougherty, D.R., Fuhrmann, M. and Colombo, P., "Accelerated Leach Test(s) Program," Annual Report, BNL-51955, Brookhaven National Laboratory, Upton, New York 11973, September 1985.

13. Fuhrmann, M., Heiser, J.H., Pietrzak, R.F., Franz, E.M., and Colombo, P., User's Guide for the Accelerated Leach Test Computer Program, BNL - 52267, Brookhaven National Laboratory, Upton, NY 11973, August 1990.

14. American Society for Testing and Materials, Standard Specification for Reagent Water, ASTM D119377, In: Part 31 "Water," 1982 Annual Book of ASTM Standards, pages 29-31, ASTM, 1916 Race Street, Philadelphia, PA 19103, 1982. 


\section{APPENDIX A}

\section{GLOSSARY}

Acceleration Factor. Ratio calculated as the time required to reach a certain Cumulative Fraction Leached for an accelerated leach test divided by the time required by a reference leach test to reach $\mathrm{t}^{1}$ at same Cumulative Fraction Leached.

Accelerated Leach Test. A leach test that provides greater release rates than those obtained through standard leach tests. Conditions such as elevated temperature and increased volume of leachant can be used to increase release rates without changing the mechanisms of leaching.

Cumulative Fraction Leached (CFL). The sum of the fractions leached during all sampling intervals calculated as:

$\mathrm{CFL}=\Sigma \mathrm{a}_{\mathrm{n}} / \mathrm{A}_{0}$

and assuming no radioactive decay.

Diffusion Coefficient. (Diffusivity) Based on Fick's Laws for diffusion, the diffusion coefficient is the ratio of the rate of transfer of a diffusing substance through the unit area of a section to the concentration gradient measured normal to the section. The diffusion coefficient is symbolized by $D$.

Diffusion Model. Computer algorithm using diffusion theory to describe leaching. Two diffusion models are used in the AlT program: diffusion from a semi-infinite medium, and diffusion from a cylinder. 
Dissolution Model. Computer algorithm that statistically analyses IFL values throughout an experiment by calculating a mean and the distribution about the mean. A consistent value of IFL indicates solubility controls on the concentration of the species of interest in the leachate.

Effective Diffusion Coefficient. (Effective Diffusivity) The diffusion coefficient that results from diffusion as it is modified by other processes (e.g. adsorption) or physical constraints (tortuosity and constrictivity). The effective diffusion coefficient is symbolized by $D_{e}$.

Finite Cylinder. (Finite Medium) A bounded body for which the diffusion equation can be solved.

Goodness-of-Fit. An expression indicating how closely a curve generated by a model represents a data curve. In the ALT program, goodnesi-of-fit is represented quantitatively (for the diffusion model and the partition model) by the value $E_{R}$. This is the sum-of-the-residuals expressed as a percentage of the final CFL of the experimental data. For the dissolution model, goodness-of-fit is indicated by the size of the distribution about a mean value of CFL. That distribution is described by the standard deviation, expressed as the coefficient of variation.

Incremental Fraction Leached (IFL). The fraction leached of a species of interest úuring a single sampling interval calculated as:

$\mathrm{IFL}=\mathrm{a}_{\mathrm{n}} / \mathrm{A}_{0}$

and assuming no radioactive decay.

Leachant. The liquid in contact with the specimien during a leach test or in contact with a waste form in the disposal environment. 
Leachate. The leachant after contacting the specimen or the waste form.

Leaching. The process (or processes) by which mass transport from a solid to a liquid takes place.

Leaching Interval. The time during which a given volume of leachant is in contact with a specimen.

Leaching Mechanism. The process which controls the rate of mass transport out of a specimen.

Partition Model. Computer algorithm, based on the diffusion models, that reduces the source term of the nodel. If the data fits this model, it implies that the species-of-interest is contained in two fractions: one leachable an: 1 the other not leachable.

Reference Leach Test. The results of a leach test conducted under defined conditions which are used as a standard for comparison with the results of other leach tests (e.g. accelerated).

Semi-dynamic Leach Test. A leach test that exposes the specimen to fresh leachant on a periodic schedule.

Semi-infinite Medium. A body, used in diffusion theory, the outer boundary of which is effectively at an infinite distance from the inner region.

Solidification Agent. A material used to process waste into a solid, stable waste form.

Source Term. The original concentration of a species of interest in a specimen or a waste form, before leaching. 
Sum-of-the-Residuals. The difference, taken at each data point, between the CFL of the model and the CFL of the data, summed through the entire data set.

Surface Area. For purposes of this test method, surface area is defined as the geometric surface area of a specimen calculated from its measured dimensions.

Volume. For purposes of this test method, volume is defined as the volume of a specimen calculated from its measured dimensions.

Waste Form. A stable, solid body formed by the waste and solidification agent and merting specifications for disposal. 

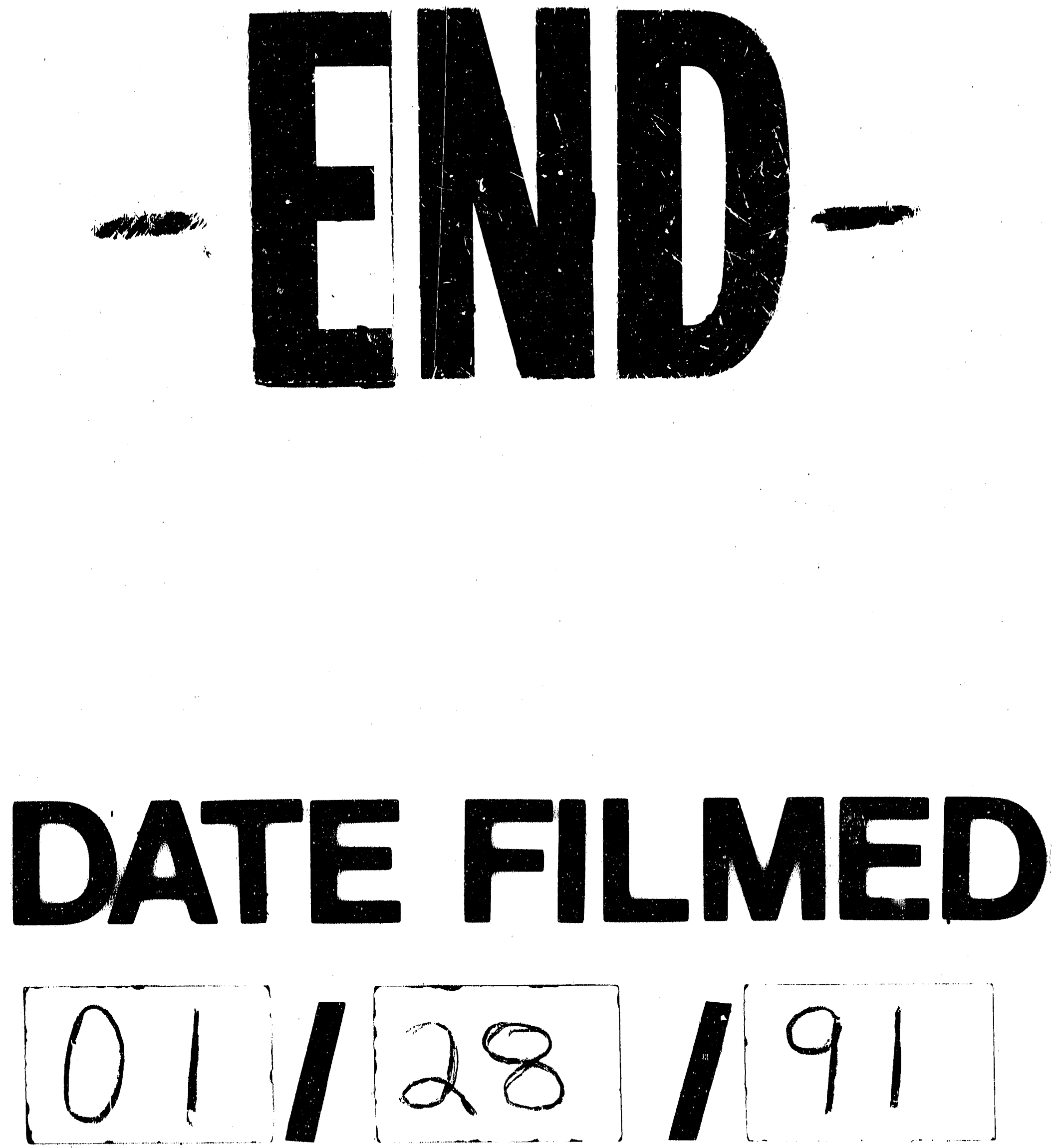
